\title{
Self-Examination of Scrotum- Need of the Hour to Create Awareness Regarding Testicular Pathologies- A Cross Sectional Study
}

\author{
Shantanu Sawale ${ }^{1}$, Meenakshi Yeola² ${ }^{2}$ Samarth Shukla ${ }^{3}$, Sourya Acharya ${ }^{4}$ \\ ${ }^{1}$ Department of Surgery, Datta Meghe Institute of Medial Sciences (Deemed to be University), Wardha, \\ Maharashtra, India. ${ }^{2}$ Department of Surgery, Datta Meghe Institute of Medial Sciences (Deemed to be \\ University), Wardha, Maharashtra, India. ${ }^{3}$ Department of Pathology, Datta Meghe Institute of Medial \\ Sciences (Deemed to be University), Wardha, Maharashtra, India. ${ }^{4}$ Department of Medicine, Datta Meghe \\ Institute of Medial Sciences (Deemed to be University), Wardha, Maharashtra, India.
}

\section{ABSTRACT}

\section{BACKGROUND}

Although nowadays people are very much concerned when it comes to cancer, still they are not aware about the process and advantages of early detection. Testicular cancer is the most common cancer among males in the age group 18-50 years. Still people are not aware of self-examination of scrotum and testicular self-examination (TSE). Knowledge deficits and sociocultural norms contribute towards increased incidence of testicular pathologies. This study was aimed to assess knowledge and attitude of young male medical students regarding self-examination of scrotum/testis and various testicular pathologies.

\section{METHODS}

A cross sectional study was conducted in a rural tertiary care hospital attached to medical college. After getting approval from institutional ethics committee, 149 medical students were included in the study. A self-administered validated online questionnaire was made for pre-test and post-test consisting of 10 questions. The students were educated after pre-test and intervention was done in post-test. The data was collected through Google forms and data analysis was done using chi square test.

\section{RESULTS}

In pre-test it was revealed that $39.5 \%$ of subjects didn't have knowledge about selfexamination of scrotum or testicles. Amongst $60.5 \%$ who knew about it, only $26.5 \%$ knew the procedure for performing the self-examination, and $24 \%$ knew the frequency for self-examination. The main barrier for $22.4 \%$ people was social and mental hindrance. In post-test, it revealed that still $11.41 \%$ didn't have clear idea about procedure of self-examination and still after knowing all the advantages $12.08 \%$ people had social or mental hindrance.

\section{CONCLUSIONS}

This study concluded health care professionals lack the necessary knowledge about TSE. Still the main problem lies in their perspective and attitude towards TSE as even after educating them regarding TSE and various testicular pathologies and its early detection and its advantages, $12.08 \%$ of students had social or mental hindrance. This study highlighted the various hindrances the educated, young, health care students have, where the real problem lies, and brings out the most important hindrance which is mental and social inhibition.

\author{
Corresponding Author: \\ Dr. Sourya Acharya, \\ Department of Medicine, \\ Datta Meghe Institute of Medial Sciences, \\ (Deemed to be University), \\ Wardha, Maharashtra, India. \\ E-mail: souryaacharya74@gmail.com
}

DOI: $10.14260 / \mathrm{jemds} / 2020 / 334$

Financial or Other Competing Interests: None.

How to Cite This Article:

Sawale S, Yeola M, Shukla S, et al. Selfexamination of scrotum- need of the hour to create awareness regarding testicular pathologies- a cross sectional study. J. Evolution Med. Dent. Sci. 2020;9(19): 1528-1532, DOI:

\section{KEY WORDS}

TES, Scrotum, Pathology, Testis, Cancer 


\section{BACKGROUND}

In today's modern world where there is so much advancement in technology and newer modalities still people are not ready to talk about their personal health, they knowingly or unknowingly ignore it. When it comes to the word "cancer" people are scared about it but still they don't take preventive or basic measures for its early detection. Amongst various diseases, "cancer" has become a big threat to human beings globally. Cancer is the second most common disease in India responsible for about 0.3 million deaths per year ${ }^{1}$. Oral cancers, breast cancers are already in rise in India. ${ }^{2-5}$

Most of the cancers are treatable if it is detected at an early stage. Testicular cancer is commonly prevailing cancer in young men (aged between 20-45 years) and recent lifestyle suggest an increase throughout the world. Testicular cancer is highly treatable, whereas the late diagnosis can lead to poor outcome. 6 Testicular Cancer (TC) begins when normal cells in a testicle change and grow uncontrollably and form a tumour. Germ cell tumour which develops in the sperm producing cell is the most common type of testicular cancer by accounting around 95\%. Painless swelling in the testicles, a dull ache in scrotum and feeling of heaviness in the scrotum are the most common symptoms of TC. Having a family history of testicular cancer and being born with undescended testicles are expected to increase the risk of developing TC among men. ${ }^{7}$ Males who find a lump in its early stages frequently have a better prognosis, with 5 -years survival rates $>95 \%$. However, men usually delay seeking treatment for TC for an average of 16 weeks after symptoms develop because of the failure and fear of death. ${ }^{7}$

Thus, it is recommended that once in month selfexamination of scrotum may also lead to early detection of various testicular anomalies other than cancer like benign tumours, spermatocele, varicoceles and other anomalies, some of which may affect fertility. To recognize the significance of their symptoms factors such as embarrassment, lack of time, fear of cancer in the subjects should be subsided.

The main objective behind this project is assessment of the medical students regarding their knowledge and attitude regarding testicular pathologies its self-examination and its advantages on early detection in treatment. As before educating patients or public regarding self-examination and testicular pathologies it very important to assess the perspective of public health care providers like medical students who create awareness among people. As a recent study reported that $89 \%$ of the risk group (adult men below age 35) had never performed testicular self-examination (TSE), and only $4 \%$ knew that men in the 18- to 50-year-old age group should perform TSE every month. ${ }^{8}$ The lack of health education provided in this area by healthcare workers is thought to contribute to delays in diagnosis. Unfamiliarity with the practice of TSE in this part of the world is attributable to professional healthcare provider's lack of attention and activity toward providing TSE education to their patients. ${ }^{9}$
This study design was undertaken to get a brief knowledge and attitude of students regarding it. A pre-test was taken which assess their knowledge and after they were educated by giving a tutorial, regarding which further a post test was taken which assessed their attitude regarding selfexamination after gaining knowledge about it.

The aim of this study was to assess their knowledge and awareness regarding various testicular pathologies, to determine the knowledge and perspective of students towards self-examination of scrotum, to educate them regarding scrotal self-examination and its benefits and to assess and understand their attitude towards selfexamination after educating them.

\section{METHODS}

This is a cross sectional study conducted among undergraduate male students of the faculty of medicine in a medical college associated with tertiary health care hospital in Wardha district of central India over a period of two months- June and July of the year 2019 after obtaining Institutional ethical committee clearance.

\section{Inclusion Criteria}

1. All individuals with no past history of testicular pathologies / lesions.

2. Individuals who are willing to take part in study.

3. Individuals falling in the age group 17-25 years.

\section{Exclusion Criteria}

4. Any individual who had any congenital or pathological lesions/procedure in testicular genital area in the past.

5. Individuals who express their unwillingness to take part in study.

6. Individuals who were below 17 and above 25 .

\section{Sample Size}

The sample size used for the study was 149 . Sample size was taken based on the convenience of the study.

\section{Procedure}

The procedure was conducted in 4 phases during these 2 months of study.

\section{Phase 1- To Assess Knowledge of Students}

To assess the knowledge and perspective of students regarding self-examination of scrotum and about various testicular pathologies with the help of a questionnaire which included their knowledge regarding the scrotum and its contents, testicular pathologies and hindrances/barriers for self-examination. The questionnaire was validated by two surgeons and one epidemiologist of the university. 


\section{Phase 2- To Educate Them Regarding Self-Examination}

To educate students about self-examination of scrotum with the help of a demonstration ${ }^{7}$ by a senior faculty member from the department of surgery

\section{Phase 3- To Assess Their Awareness after Intervention}

Assessment of their awareness regarding self-examination of scrotum is done along with their changed perspective towards early detection of testicular pathologies

\section{Ethical Consideration and Consent to Participate}

The research proposal was approved by the Institutional Human Ethics Committee of the medical college associated with tertiary health care hospital. A written permission was obtained from the principal and ethical committee. The investigator explained about the study to the students and a verbal consent was obtained from the students.

\section{Data Collection}

The data was collected in the form of pre-test and post-test questionnaire which was made on the basis of extensive literature. The questionnaire was made in English language which consisted of close ended questions having only two options of "yes" and "no". The questionnaire was made with the help of online Google forms in which authenticity was done by adding a mandatory email id requirement as these online forms were more feasible for data collection in the form of spreadsheet.

\section{Statistical Analysis}

Statistical analysis was done using descriptive statistics using non-parametric test "chi-square test" and results were analysed by percentage where ever applicable.

\section{RESULTS}

In this study a total of 149 study subjects participated after taking verbal consent which were in the age group of 18-24 as all were students of medical college associated with tertiary hospital. The pre-test and post-test were analysed by the chi square test method.

First a pre-test was taken to assess their knowledge which revealed that $39.5 \%$ of subjects have didn't had knowledge about self-examination of scrotum or testicles only $60.5 \%$ knew about it. Amongst $60.5 \%$, only $26.5 \%$ knew the procedure for performing the self-examination and $24 \%$ knew the frequency for self-examination still, a majority of people around $81.6 \%$ people knew about testicular pathologies but only $50.3 \%$ people knew about its clinical diagnosis. Even after getting brief idea about the topic and test questionnaire when asked about early detection and advantages in testicular pathologies $18.4 \%$ and $28.6 \%$ didn't knew about it respectively. The main barrier for $22.4 \%$ people was social and mental hindrance (Table 1)

\begin{tabular}{|c|c|c|c|c|c|}
\hline \multirow{2}{*}{$\begin{array}{l}\text { Sl. } \\
\text { No. }\end{array}$} & \multirow{2}{*}{ Questions } & \multicolumn{2}{|c|}{ Pre-Test } & \multicolumn{2}{|c|}{ Post Test } \\
\hline & & Yes & No & Yes & No \\
\hline 1 & Knowledge about self-examination & $85 \%$ & $15 \%$ & $100 \%$ & $0 \%$ \\
\hline 2 & $\begin{array}{l}\text { Knowledge about self-examination } \\
\text { of scrotum }\end{array}$ & $60.5 \%$ & $39.5 \%$ & $99.33 \%$ & $0.67 \%$ \\
\hline 3 & Procedure for TSE & $26.5 \%$ & $73.5 \%$ & $88.59 \%$ & $11.41 \%$ \\
\hline 4 & Frequency for self-examination & $24 \%$ & & $5.97 \%$ & $.03 \%$ \\
\hline 5 & $\begin{array}{l}\text { Knowledge about testicular } \\
\text { pathologies }\end{array}$ & $81.6 \%$ & $18.4 \%$ & $93.96 \%$ & $6.04 \%$ \\
\hline 6 & $\begin{array}{l}\text { Knowledge of clinical diagnosis of } \\
\text { testicular pathologies }\end{array}$ & $50.3 \%$ & $49.7 \%$ & $92.62 \%$ & $7.83 \%$ \\
\hline 7 & $\begin{array}{l}\text { Knowledge about investigations } \\
\text { for testicular pathologies }\end{array}$ & $73.3 \%$ & $26.7 \%$ & $98.66 \%$ & $1.34 \%$ \\
\hline 8 & $\begin{array}{l}\text { Knowledge about early detection } \\
\text { for testicular diseases }\end{array}$ & $81.6 \%$ & $18.4 \%$ & $97.99 \%$ & $2.01 \%$ \\
\hline 9 & $\begin{array}{l}\text { Knowledge about advantages of } \\
\text { early detection }\end{array}$ & $71.4 \%$ & $28.6 \%$ & $93.29 \%$ & $6.71 \%$ \\
\hline 10 & $\begin{array}{l}\text { Mental or social hindrance for } \\
\text { doing TSE }\end{array}$ & $22.4 \%$ & $77.6 \%$ & $12.08 \%$ & $87.92 \%$ \\
\hline & Tot Ct & & & & \\
\hline
\end{tabular}

After educating them regarding self-examination and its advantages and various pathologies associated with it a post test was taken which revealed that still $11.41 \%$ still didn't had clear idea about procedure of self-examination and still after knowing all the advantages $12.08 \%$ people had social or mental hindrance.

\section{DISCUSSION}

The study suggests that about $39.5 \%$ students didn't had knowledge about TSE in pre-test which is slightly less than that of study carried out on 101 Australian University Students on awareness of TSE which reported that out of the 108 respondents, 59 (58.4\%) had heard of testicular selfexamination before the survey while only $42(41.6 \%)$ had never heard of TSE. 10 The finding is also in line with the work of in Turkey on 484 Turkish male university students to determine the inadequate knowledge of TSE. The result of the study states $(68 \%)$ of the respondents reported that they did not know about Testicular Self-Examination. ${ }^{11}$ However, the result is in contrast with the study in University of Port Harcourt, Rivers State on 750 males aged 18-50 years. The study revealed that knowledge (awareness) of TSE and TC was poor. Only $69(9.2 \%)$ of the respondents were aware that testicular lump could be a sign of TC. 12 The vast difference may be due to different socio demographic status and literary rate in the following country which leads to more awareness among students and people from the childhood itself. The need of an hour is to create awareness among medical students as they are the one who are going to create awareness among their patients and general public but firstly they should be made aware of it. They reported that only $18 \%$ of the physicians in a variety of specialties taught TSE to their patients regularly. The most common reason cited (82\%) for not teaching TSE was being unfamiliar with the technique or never having thought about it, similar to our results. ${ }^{13}$ A study by Singer et al surveyed 200 Israeli male military physicians regarding their testicular cancer knowledge, awareness, and TSE practices. Of the 70 (35\% of the potential sample) respondents, only $16 \%$ taught their patients about the importance of TSE. ${ }^{14}$ The percentage who actually taught the TSE technique was not reported. One possible explanation for the increased prevalence of teaching TSE in the current study is an increased public awareness regarding the risks of testicular cancer and increased 
teaching in training programs through rotations such as adolescent medicine during the past decade. ${ }^{15}$ Even though some of the students who were not knowing TSE were aware about testicular pathologies which consisted of $81.6 \%$. Although, most of them knew about investigations for testicular pathologies but they didn't know about clinical diagnosis of TS which were about $49.7 \%$. After answering these questions when they were asked about early detection and advantages of TSE, even though $39.5 \%$ said they didn't had knowledge about TSE still they answered positively which were almost $81.6 \%$ for early detection and $71.4 \%$ for advantages which was considered due to the fact that they got the understanding from the previous questions regarding TSE and TS. For almost $22.4 \%$ students, social or mental hindrance was the main barrier for performing TSE. After educating them regarding procedure of TSE and various testicular pathologies and advantages of early detection, a post test was taken which surprisingly revealed that even after educating them, still $11.41 \%$ didn't understood the procedure for TSE the reasons cited for which were lack of attention during demonstration, unwillingness to learn the procedure. Other all responses were positive in post-test with a slight difference. The most important was the social or mental hindrance which was again the main barrier for $12.08 \%$ for performing TSE even after knowing the advantages of early detection and all the testicular pathologies. The study subjects were medical students who have more knowledge and awareness regarding diseases and its complications still if they are facing the social or mental hindrance then what kind of barriers normal people must be facing which leads to less early detection of testicular pathologies and TC. It is need of an hour to rethink that only giving knowledge about TSE alone won't help overcome this problem or making aware them about TC or TSE. ${ }^{15}$ Along with educating them regarding this, it is very important to change their attitude and perspective towards TSE and help them overcoming their social or mental hindrances. The limitation of this study was it being only conducted on a small sample size of single medical college. Still a lot work has to be done with respect to changing perspective of students.

\section{CONCLUSIONS}

In a developing country like India, there are still some societies which lack proper knowledge regarding health care and preventive measures for diseases. The main people responsible for educating laymen regarding this are health care professionals. As in today's scenario, people don't know much about TC or TSE and the incidence of TC and various testicular pathologies is increasing day by day. It is very important to create awareness and educate them regarding TSE and various testicular pathologies. But before that the knowledge and perspective of medical students should be clear. On the basis of this study it is seen that even after being health care professionals, they lack the necessary knowledge about TSE. The main problem lies in their perspective and attitude towards TSE as even after educating them regarding TSE and various testicular pathologies and it early detection and its advantages, still $12.08 \%$ of students are facing social or mental hindrance. This study highlighted the various hindrances the educated, young, health care students have, where the real problem lies, and brings out the most important hindrance which is mental and social inhibition.

\section{REFERENCES}

[1] Ali I, Waseem, Wani A, Saleem K. 'Cancer Scenario in India with Future Perspectives' Cancer Therapy. 2011; 8: 56-70.

[2] Valan PA. A study to assess the effectiveness of information education communication package on knowledge and attitude regarding testicular cancer and testicular self-examination among students in a selected college at Nagercoil. IOSR Journal of Nursing and Health Science (IOSR-JNHS) 2016;5(6):19-23.

[3] Gondivkar SM, Bhowate RR, Gadbail AR, et al. Quality of life and oral potentially malignant disorders: critical appraisal and prospects. World J Clin Oncol 2018;9(4):56-9.

[4] Kadashetti V, Shivkumar KM, Chaudhary M, et al. Influence of risk factors on patients suffering from potentially malignant disorders and oral cancer: a casecontrol study. J Oral Maxillafac Pathol 2017;21(3):455-6.

[5] Suwana DK. Clinical aspects of oral cancer: a case report series. Dent Med Probl 2017;54(1):85-9.

[6] Shaheed R, Shukla S, Acharya S, et al. Journey from fighters to survivors: quality of life and mental status in cancer patients in a rural tertiary care hospital. 2019;13(8):XC01-XC04.

[7] American Society of Clinical Oncology. Testicular Cancer 2014. https://www.cancer.net/cancer-types/testicularcancer

[8] Akar SZ, Bebis H. Evaluation of the effectiveness of testicular cancer and testicular self-examination training for patient care personnel: intervention study. Health Education Research 2014;29(6):966-76.

[9] Gleason AM. Racial disparities in testicular cancer: impact on health promotion. J Transcult Nurs 2006;17(1):58-64.

[10] Ugboma HAA, Aburoma HLS. Public awareness of testicular cancer and testicular self-examination in academic environments: a lost opportunity. Clinics (Sao Paulo) 2011;66(7):1125-8.

[11] Testicular Self-Examination: The British Association of Urological Surgeons (BAUS). https://www.baus.org.uk/_userfiles/pages/files/Patient s/Leaflets/Testicular\%20self\%20examination.pdf selfexamination.pdf

[12] Barling NR, Lehmann M. Young men's awareness, attitudes and practice of testicular self-examination: a health action process approach. Psychology Health and Medicine 1999;4(3):255-63.

[13] Ozbas A, Cavdar I, Findlk UY, et al. Inadequate knowledge levels of Turkish male university students about testicular self-examination. Asian Pac J Cancer Prev 2011;12(4):919-22. 
[14] Brenner JS, Hergenroeder AC, Kozinetz CA, et al. Teaching testicular self-examination: education and practices in pediatric residents. Pediatrics 2003;111(3):e239-e44.
[15] Singer AJ, Tichler T, Orvieto $R$, et al. Testicular carcinoma: a study of knowledge, awareness and practice of testicular self-examination in male soldiers and military physicians. Mil Med 1993;158(10):640-3. 